\title{
The Effect of Self-Transcendence on Depression in Cognitively Intact Nursing Home Patients
}

\author{
Gørill Haugan $^{1}$ and Siw Tone Innstrand ${ }^{2}$ \\ ${ }^{1}$ Research Centre for Health Promotion and Resources HiST/NTNU, Faculty of Nursing, Sør-Trøndelag University College, \\ 7004 Trondheim, Norway \\ ${ }^{2}$ Research Centre for Health Promotion and Resources HiST/NTNU, Department of Social Work and Health Science, \\ Norwegian University of Science and Technology, 7491 Trondheim, Norway \\ Correspondence should be addressed to Gørill Haugan, gorill.haugan@hist.no
}

Received 20 January 2012; Accepted 28 February 2012

Academic Editors: B. Camarena, C. Toni, and A. Vance

Copyright ( 2012 G. Haugan and S. T. Innstrand. This is an open access article distributed under the Creative Commons Attribution License, which permits unrestricted use, distribution, and reproduction in any medium, provided the original work is properly cited.

\begin{abstract}
Aims. This study's aim was to test the effects of self-transcendence on depression among cognitively intact nursing home patients. Background. Depression is considered the most frequent mental disorder among the elderly population. Specifically, the depression rate among nursing home patients is three to four times higher than that among community-dwelling elderly. Therefore, finding new and alternative ways to prevent and decrease depression is of great importance for nursing home patients' well-being. Selftranscendence is related to spiritual as well as nonspiritual factors, and it is described as a correlate and resource for well-being among vulnerable populations and at the end of life. Methods. A two-factor construct of the self-transcendence scale (interpersonal and intrapersonal) and the hospital anxiety and depression scale (HADS) was applied. A sample of 202 cognitively intact nursing home patients in central Norway was selected to respond to the questionnaires in 2008/2009. Results. A hypothesized SEM model demonstrated significant direct relationships and total effects of self-transcendence on depression. Conclusion and Implication for Practice. Facilitating patients' self-transcendence, both interpersonally and intrapersonally, might decrease depression among cognitively intact nursing home patients.
\end{abstract}

\section{Introduction}

In the next 30 years, the number of people over 65 in the world will almost double to 1.3 billion [1]. Moreover, the most rapidly growing segment is people over 80 . By 2050 the percentage of those 80 and older will be $31 \%$, while the number was $18 \%$ in 1980 [2]. This huge shift to an older population globally has given rise to the notions of the "third" and "fourth" ages in the lifespan development literature [3]. This differentiation of the last part of the lifespan into two separate phases is important because of the characteristic patterns of gains (growth) and losses (decline) seen in the "young old" and the "old old" [4]. For many of those in the fourth age (80+) issues such as physical illness and approaching mortality decimate their functioning and subsequently lead to the need for nursing home $(\mathrm{NH})$ care.
Depression is one of the most prevalent mentally ill health problems facing European citizens today [5], and it is considered one of the most frequent mental disorders in the elderly population. Moreover, depression is particularly common among these living in long-term care facilities [6]. Reported rates of major depression in older adults, depending on the location and characteristics of the sample, have ranged from $1 \%$ to $42 \%$ [7]. In general, the prevalence of late-life depression has been found to be higher in those patients with more medical illness. Specifically, rates of depression in NHs are three to four times higher than those in community-dwelling older adults [8]. Also, elderly who lack social/emotional support tends to be more depressed [9]. A review that included 36 studies from various countries reported a prevalence rate for major depression ranging from $6 \%$ to $26 \%$ and for minor depression from $11 \%$ to $50 \%$. The 
prevalence rate of depressive symptoms ranged from $36 \%$ to $49 \%$ [10].

A linear increase of prevalence of depression with increasing age is described [11]. The three strongest explanatory factors on the age-effect of depression found are impairment, diagnosis, and somatic symptoms, respectively $[11,12]$. Worse general medical health is seen as the strongest factor associated with depression among NH patients [13]. In general, $\mathrm{NH}$ patients are characterized by high age, frailty, mortality, disability, powerlessness, and dependency. Therefore, they are particularly vulnerable and more likely to become depressed. Moreover, studies in nursing homes report a large overlap of depression and anxiety [14-17]. The course of major depression and significant depressive symptoms in $\mathrm{NH}$ patients tends to be chronic, with a persistence rate of more than $50 \%$ of depressed patients still depressed after 6-12 months [18, 19].

Depression in $\mathrm{NH}$ patients is associated with negative outcomes such as impaired quality of life [20], impaired activities of daily living, substantial caregiver burden and worsened medical outcomes [21], increased risk of hospital admission [22], and a higher mortality rate [23]. A recent study reports that the presence of depression has a statistically and clinically significant negative impact on wellbeing [24]. The NH patients' sense of loss of independence and privacy, feelings of isolation and loneliness, the ever present death and grief, and lack of meaningful in-house activities are identified as risk factors for depression. Conversely, $\mathrm{NH}$ in-house activities and different kinds of mental health services have significant benefit for $\mathrm{NH}$ patients at risk for depression [25-27]. Accordingly, efforts to prevent and decrease depression are of great importance for $\mathrm{NH}$ patients' well-being and quality of life. The World Health Organization [28] has estimated that by 2020, depression is expected to be the highest ranking cause of disease in the developed world. Therefore, finding new and alternative approaches to weaken this detrimental development is highly warranted.

Self-transcendence is found to be such a correlate and a resource for well-being among vulnerable populations and at the end of life [29-31]. Self-transcendence includes a psycho-social-spiritual force toward personal maturity that is distinct from the more self-absorbed strivings for selfesteem and intimacy typical in earlier developmental phases. Hence, self-transcendence enhances an individual's searching for new perspectives, meaning, and well-being and allows him or her to overcome ego concerns. The idea of selftranscendence is inspired by human developmental theory emphasizing maturity as the developmental task in later life [32]. In accordance with this theory, the developmental crisis in old age entails integrity versus despair and is resolved by the development of inner resources as personal maturity and wisdom, qualities providing well-being. The developmental process of self-transcendence is stimulated by the challenges of age and coming to terms with death. Adults with higher levels of self-transcendence do not seek absolute answers to questions in life but seek meaning in life events as integrated within a moral, social, and historical context [33].
The central core of self-transcendence is described as connection between the individual, environment, and a transcendent being [33]. Self-transcendence refers to a multidimensional expansion of the self-boundaries intrapersonally (through self-acceptance and finding meaning in life), interpersonally (by reaching out to others or connecting with nature), transpersonally (by reaching out to a higher entity, being of purpose), and temporality (by integrating one's past and future into the present; a dynamic process involving adaption to physical, emotional, and/or spiritual distress). Within a holistic framework of the body, mind, and spirit as a whole, self-transcendence has been considered a central aspect of human spirituality [34]. As a general human dimension of personal maturity, self-transcendence has been related to spiritual and nonspiritual factors. Human spirituality is expressed and experienced in the context of caring connections with the self, others, nature, and a life force or God [35-39]. Accordingly, spirituality seems closely related to connectedness, the essence of self-transcendence. A recent study of the relationships between spiritual well-being and self-transcendence revealed that both interpersonal and intrapersonal self-transcendence significantly affect spiritual well-being in cognitively intact $\mathrm{NH}$ patients [40].

Self-transcendence has been studied in various disciplines, but it is of particular interest to nursing. The perspective of promoting health and well-being is fundamental and a major nursing concern in long-term care [41-43]. Studies on various populations demonstrate an inverse association between depression and self-transcendence [30, 31, 4449]. Previous research demonstrates the significance of selftranscendence to older people well-being [31, 45, 50, 51]. Empirical support for the importance of self-transcendence for those at the end of life and facing their own mortality has been well documented [33, 47, 52-55].

In summary, the literature suggests depression as a common mental disorder among older people characterized by high age, impairment, and somatic symptoms. The patients' sense of loss of independence and privacy, feelings of isolation and loneliness, and lack of meaningful activities are risk factors for depression in NH patients. Selftranscendence is a resource for well-being among vulnerable individuals and at the end of life. A previous investigation of the dimensionality of the self-transcendence scale revealed that self-transcendence comprises one interpersonal and one intrapersonal factor [56]. Therefore, this study investigates the associations between interpersonal and intrapersonal self-transcendence and depression among cognitively intact NH patients. To the authors' knowledge, previous research has not examined the relationships between interpersonal and intrapersonal self-transcendence and depression in NHs by means of structural equation modelling (SEM). Our research question was does self-transcendence affect depression in cognitively intact NH patients? Based on the theoretical and empirical knowledge of depression and self-transcendence, the following hypotheses were formulated.

Hypothesis 1. Intrapersonal self-transcendence has negative effect on depression among cognitively intact $\mathrm{NH}$ patients. 
Hypothesis 2. Interpersonal self-transcendence has negative effect on depression among cognitively intact $\mathrm{NH}$ patients.

\section{Methods}

2.1. Design and Ethical Considerations. The data were collected in 2008-2009 from $250 \mathrm{NH}$ patients who met the inclusion criteria: (1) local authority's decision of longterm NH care, (2) residential time 6 months or longer, (3) informed consent competency recognized by responsible doctor and nurse, and (4) capable of being interviewed. The NH patients were approached by a head nurse they knew well. The nurse presented them with oral and written information about their rights as participants and their right to withdraw at any moment. Each participant provided informed consent. This population has difficulties completing a questionnaire on their own; therefore one-on-one interviews were conducted by three trained researchers and completed in the $\mathrm{NH}$ patients' private rooms. Researchers with identical professional background were chosen (RN, MA, trained and experienced in communication with elderly, as well as teaching gerontology at an advanced level) and trained to conduct the interviews as similarly as possible. Statistical correlational tests showed no significant differences between responses based on interviewers. The questionnaires relevant for the present study were part of a battery of nine questionnaires comprising 130 items. Interviewers held a large-print copy of questions and possible responses in front of the participants to avoid misunderstandings. Approval by the Norwegian Social Science Data Services was obtained for a license to maintain a register containing personal data (ref. no. 16443), and likewise we attained approval from The Regional Committee for Medical and Health Research Ethics in Central Norway (ref. no. 4.2007.645) as well as the directory of the 44 NHs.

2.2. Participants. The total sample consisted of $202(80.8 \%)$ of 250 long-term $\mathrm{NH}$ patients representing $44 \mathrm{NHs}$. Longterm $\mathrm{NH}$ care was defined as 24-hour care; short-term care patients, rehabilitations patients, and cognitively impaired patients were not included. Participants' ages ranged from 65 to 104 years, with a mean of 86 years $(\mathrm{SD}=7.65)$. The sample consisted of 146 women (72.3\%) and 56 men $(27.7 \%)$, where the mean age for women was 87.3 years and 82 years for the men. In total, 38 (19\%) were married/cohabitant, 135 (67\%) widows/widowers, 11 (5.5\%) divorced, and 18 (19\%) were single. The mean residential time when interviewed was 2.6 years for both sexes (range 0.5-13 years); 117 stayed in rural NHs, while 85 stayed in urban NHs. In all, 26.1\% showed mild to moderate depression, only one woman scored $15+$ indicating severe depression, $70.4 \%$ was not depressed, and nearly $88 \%$ had no anxiety disorder. Missing data was low in frequency: depression $5.0 \%$ and self-transcendence scale $5.9 \%$ and were handled by means of the listwise procedure.

2.3. Measures. Depression was assessed by the depression subscale of the hospital anxiety and depression scale
(HADS), comprising seven items. Each item is scored from $0-3$, and the maximum score is 21 on the subscale. The ranges of scores for cases are 0-7 normal, 8-10 mild disorder, 11-14 moderate disorder, and 15-21 severe disorder [57]. HADS has been tested extensively and has wellestablished psychometric properties [58]. In order to increase acceptability and avoid individuals feeling as though they are being tested for mental disorders, symptoms of severe psychopathology have been excluded. This makes HADS more sensitive to milder psychopathology [11]. HADS is translated into Norwegian and found to be valid for older people $[11,12]$. Since the present study focuses on the associations between self-transcendence and depression, only the depression-items (subscale HADS-D) were included in the SEM model to be tested here. Sample items are "I still enjoy the things I used to enjoy," "I can laugh and see the funny side of things," "I feel cheerful," "I feel as I'm slowed down," "I have lost interest in my appearance," and "I look forward with enjoyment to things." The item "I can enjoy a good book or television-program" loaded very low $(\lambda=0.20$, $R^{2}=0.05$ ), indicating less relevance for depression in this $\mathrm{NH}$ population and was dismissed. As the in-house activities in NHs are scarce, TV programs might be the only activity available, while reading books is difficult due to impairments. The items were scored on a four-point scale ranging from totally disagree to totally agree. The internal consistence of the construct (Table 1$)$ was satisfactory $(\alpha=.68)$.

Interpersonal and intrapersonal self-transcendence were assessed by items from the self-transcendence scale (STS). The STS was developed from the 36-item Developmental Resources of Later Adulthood Scale [33, 59], which intended to identify intrapersonal, interpersonal, transpersonal, and temporal experiences characteristic of later life, reflecting expanded boundaries of self [46]. The STS comprises 15 items measuring characteristics of a matured view of life representing the extent to which a person expands personal boundaries. Each item is rated on a four-point Likerttype scale from 1.0 (not at all) to 4.0 (very $m u c h$ ), with higher scores indicating higher ST (see the Supplemental Information in Supplementary Material available online at doi:10.5402/2012/301325). In previous studies, Cronbach's $\alpha$ ranged from. 80 to.88 [31, 43, 48]. Content validity is adequate, based on a thorough review of empirical and theoretical literature [33]. Support for construct validity has been found in the relationships of self-transcendence scores to other measures $[29,60,61]$.

The STS was translated into Swedish and back into English, and the back-translated version was then approved by the instrument constructor [62]. The Swedish version demonstrated internal consistency of.70-.85 (op.cit.) and was translated into Norwegian for the purposes of the present study. The Swedish and Norwegian language and culture are nearly identical in all aspects that matter this study. The STS is practically unchanged in the Norwegian version, but the words are spelled in Norwegian and the meanings have been checked. The two-factor construct of self-transcendence [56] was used, but the number of items was reduced; the item "letting go of my past losses" (ST15), which is reversed scored, loaded extremely low $(\lambda=0.11)$ 
TABLE 1: Means (M), standard deviations (SD), Cronbach's alpha, and correlation coefficients for the study variables.

\begin{tabular}{lccccc}
\hline Construct & M & SD & Cronbach's alpha & ST-1 & ST-2 \\
\hline ST-1 (7 items) & 2.54 & 0.58 & .76 & - & HADS-D \\
ST-2 (7 items) & 3.04 & 0.42 & .65 & $0.29^{*}$ & - \\
HADS-D (6 items) & 2.32 & 0.39 & .68 & $0.43^{*}$ & $0.50^{*}$ \\
Self-transcendence (15 items) & 2.85 & 0.34 & .72 & & \\
\hline
\end{tabular}

Note: ST-1: interpersonal self-transcendence. ST-2: intrapersonal self-transcendence. HADS-D: depression. * Significant at the 0.05 level.

and demonstrated $R^{2}=0.02$. This item was uncorrelated; therefore, there might be some translation problems and this item was dismissed. The items "Having hobbies and interests I can enjoy," "Being involved with other people," "Sharing my wisdom or experience with others," "Helping others in some way," "Having an ongoing interest in learning," "Able to move beyond things that once seemed so important," and "Finding meaning in my spiritual beliefs" were indicators for interpersonal self-transcendence, while the items "Accepting myself as growing older," "Adjusting well to my present life situation," "Adjusting well to changes in my physical abilities," "Finding meaning in my past experiences," "Accepting death as a part of life," "Letting others help me when I may need it," and "Enjoying my pace of life" constituted the intrapersonal ST construct. Cronbach's $\alpha$ in current study was 0.72 (all 15 items), while $\alpha$ for interpersonal selftranscendence (seven items) was . 76 and .65 for intrapersonal self-transcendence (seven items) (Table 1). Reliability for the latent constructs in this study is further investigated inside the confirmatory factor analysis (CFA). Composite reliability $\left(\rho_{c}\right)$ is reported in Table 2 displaying values between 0.65 and 0.75 ; values greater than 0.60 are desirable [63].

2.4. Statistical Analysis. A structural equation model (SEM) of the hypothesized relations between the latent constructs of depression and self-transcendence was tested by means of LISREL 8.8 [64]. Using SEM accounts for random measurement error, and the psychometric properties of the scales in the model are more accurately derived. Since the standard errors are estimated under nonnormality, the Satorra-Bentler-scaled chi-square statistic was applied as a goodness-of-fit statistic, which is the correct asymptotic mean even under nonnormality [65]. In line with the rules of thumb of conventional cut-off criteria [66], the following fit indices were used to evaluate model fit: chi-square $\left(\chi^{2}\right)-$ a small $\chi^{2}$ and a nonsignificant $P$ value corresponds to good fit [64]. Also, we used the root mean square error of approximation (RMSEA) and the standardized root mean square residual (SRMS) with values below 0.05 indicating good fit, while values smaller than 0.08 are interpreted as acceptable $[66,67]$. The comparative fit index (CFI) and the nonnormed fit index (NNFI) with an acceptable fit at 0.95 and good fit at 0.97 and above were used, and the normed fit index (NFI) and the goodness-of-fit index (GFI) with an acceptable fit at 0.90 , while a good fit was set to 0.95 . For the adjusted GFI (AGFI), acceptable fit was set to 0.85 and good fit at 0.90 (op.cit.).

Before examining the hypothesized relationships in the SEM analysis, the measurement models were tested by
TABLE 2: Measurement models included in Model 1: interpersonal self-transcendence (ST-1) and intrapersonal self-transcendence (ST-2) to depression (HADS-D). Standardized factor loadings and $t$-values. Squared multiple correlations $\left(R^{2}\right)$. Composite reliability ${ }^{1}$ $\left(\rho_{c}\right)$.

\begin{tabular}{|c|c|c|c|c|}
\hline Items & Parameter & $\begin{array}{l}\text { LISREL } \\
\text { estimate }\end{array}$ & $t$-value & $R^{2}$ \\
\hline \multicolumn{5}{|l|}{ ST-1 } \\
\hline ST1 & $\lambda x 1,1$ & 0.54 & $5.95^{*}$ & 0.28 \\
\hline ST3 & $\lambda \times 3,1$ & 0.67 & $9.39 *$ & 0.44 \\
\hline ST6 & $\lambda x 6,1$ & 0.71 & $9.02 *$ & 0.52 \\
\hline ST8 & $\lambda x 8,1$ & 0.54 & $6.12^{*}$ & 0.30 \\
\hline ST9 & $\lambda x 9,1$ & 0.58 & $7.85^{*}$ & 0.33 \\
\hline ST10 & $\lambda \times 10,1$ & 0.41 & $4.65^{*}$ & 0.16 \\
\hline ST12 & $\lambda \times 12,1$ & 0.33 & $3.90^{*}$ & 0.11 \\
\hline \multicolumn{5}{|l|}{ ST-2 } \\
\hline ST2 & $\lambda \times 2,2$ & 0.45 & $4.66^{*}$ & 0.20 \\
\hline ST4 & $\lambda x 4,2$ & 0.77 & $7.55^{*}$ & 0.59 \\
\hline ST5 & $\lambda x 5,2$ & 0.60 & $6.08^{*}$ & 0.37 \\
\hline ST7 & $\lambda \times 7,2$ & 0.40 & $3.88^{*}$ & 0.16 \\
\hline ST11 & $\lambda x 11,2$ & 0.25 & $2.58^{*}$ & 0.06 \\
\hline ST13 & $\lambda \times 13,2$ & 0.37 & $3.60 *$ & 0.14 \\
\hline ST14 & $\lambda x 14,2$ & 0.29 & $2.53^{*}$ & 0.08 \\
\hline \multicolumn{5}{|l|}{ HADS-D } \\
\hline HADS2 & $\lambda y 1,1$ & 0.70 & - & 0.49 \\
\hline HADS4 & $\lambda y 2,1$ & 0.70 & $7.48^{*}$ & 0.49 \\
\hline HADS6 & $\lambda y 3,1$ & 0.62 & $5.36^{*}$ & 0.39 \\
\hline HADS8 & $\lambda y 4,1$ & 0.32 & $3.88^{*}$ & 0.10 \\
\hline HADS10 & $\lambda y 5,1$ & 0.22 & $2.47^{*}$ & 0.05 \\
\hline HADS12 & $\lambda y 6,1$ & 0.58 & $5.27^{*}$ & 0.34 \\
\hline$\rho_{\mathrm{c}}$ ST-1 7 items & $\rho_{\mathrm{c}}$ & 0.75 & - & - \\
\hline$\rho_{\mathrm{c}}$ ST-2 7 items & $\rho_{\mathrm{c}}$ & 0.65 & - & - \\
\hline$\rho_{\mathrm{c}}$ HADS-D 6 items & $\rho_{\mathrm{c}}$ & 0.71 & - & - \\
\hline
\end{tabular}

confirmatory factor analysis (CFA). The CFA provided a good fit to the observed data for the interpersonal selftranscendence $\left(\chi^{2}=22.28, P<0.073\right.$, RMSEA $=0.055$, $\mathrm{SRMR}=0.047, \mathrm{NFI}=0.95, \mathrm{NNFI} / \mathrm{CFI}=0.97 / 0.98, \mathrm{GFI} / \mathrm{AGFI}$ $=0.96 / 0.92)$, intrapersonal self-transcendence $\left(\chi^{2}=15.77\right.$, $P<0.0033$, RMSEA $=0.026, \mathrm{SRMR}=0.056, \mathrm{NFI}=0.93$, $\mathrm{NNFI} / \mathrm{CFI}=0.99 / 0.99, \mathrm{GFI} / \mathrm{AGFI}=0.96 / 0.92)$, and the depression scale $\left(\chi^{2}=9.43, P<0.46\right.$, RMSEA $=0.016$, 


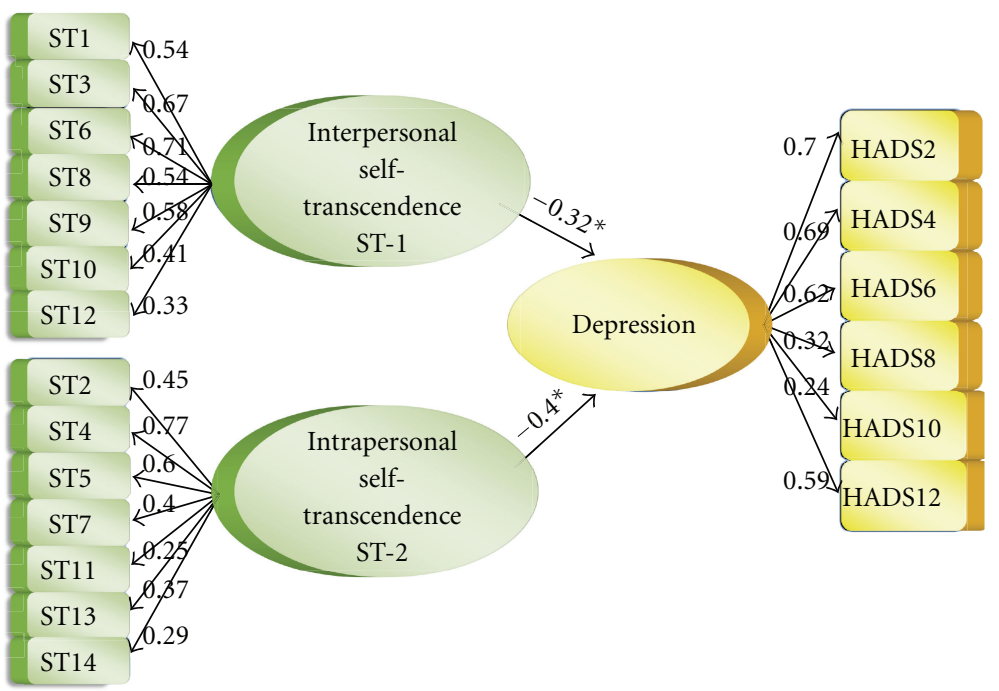

Note: ST-1: interpersonal self-transcendence, ST-2: intrapersonal self-transcendence

HADS: hospital anxiety and depression scale; the depression subscale

* Significant at the $5 \%$ level

FIGURE 1: SEM Model 1. Measurement models and directional relationships for self-transcendence (ST) to depression.

$\mathrm{SRMR}=0.039, \mathrm{NFI}=0.96, \mathrm{NNFI} / \mathrm{CFI}=1.00 / 1.00, \mathrm{GFI} / \mathrm{AGFI}$ $=0.98 / 0.95)$. All parameter estimates were significant $(P<$ 0.05 ) and loaded positively and clearly on their intended latent variable with standardized factor loadings between 0.22 and 0.77 . For scaling the variances of the dependent latent variable was set at 1 .

\section{Results}

3.1. Descriptive Analysis. Table 1 displays the means (M), standard deviations (SD), Cronbach's alpha, and correlations matrix for the constructs of self-transcendence (interpersonal and intrapersonal) and depression. The correlations between the measures were in the expected direction. Moderate correlations were found between the latent constructs included in the SEM model (Table 1). The alpha levels for the various measures indicate an acceptable level of interitem consistency in the measures [68] with Cronbach's alpha coefficients of .65 or higher.

3.2. Structural Equation Modeling (SEM). In order to investigate how interpersonal self-transcendence (ST-1) and intrapersonal self-transcendence (ST-2) relate to depression, Model 1 comprising six depression, seven interpersonal selftranscendence and seven intrapersonal self-transcendence items was estimated. Figure 1 shows Model 1 with its measurement and structural models. All estimates were significant $(P<0.05)$, and the factor loadings ranged $0.22-$ 0.72 and $R^{2}$-values $0.05-0.59$. Model 1 fitted well $\left(\chi^{2}=\right.$ 201.64, $P=0.035, \mathrm{df}=167, \mathrm{RMSEA}=0.034, P$ value $=$ $0.96, \mathrm{NNFI}=0.96, \mathrm{CFI}=0.97, \mathrm{SRMR}=0.067$, and AGFI $=0.85)$. However, NFI $=0.84$ and GFI $=0.88$ were low. Traditionally, a cut-off point of 0.90 has been recommended for the GFI and NFI. However, the AGFI, which adjusts the GFI by degrees of freedom, is acceptable. Also the NFI is sensitive to sample size, underestimating fit for samples less than 200 [69]; therefore researchers should not rely solely on the GFI and NFI [70].

Table 3 shows the standardized regression coefficients of the directional relationships and the total effects between the latent constructs in Model 1. As hypothesized, both directional paths were significant displaying an inverse relationship, from interpersonal self-transcendence to depression $\left(\gamma 1,1=-0.30^{*}\right)$ and from intrapersonal self-transcendence to depression $\left(\gamma 1,2=-0.41^{*}\right)$ (Table 3$)$.

A scrutiny of the total effects of interpersonal selftranscendence and intrapersonal self-transcendence on depression revealed statistical significant total effects from both interpersonal and intrapersonal self-transcendence on all the depression items (Table 3). No indirect effects were displayed.

\section{Discussion}

The World Health Organization [28] estimated that, by 2020, depression will be the highest ranking cause of disease in the developed world. Therefore, finding new and alternative approaches to weaken this development is necessary. Moreover, a huge shift to an older population worldwide is highlighted, and the most rapidly growing segment is that of people over 80 years old. Simultaneously, depression is one of the most frequent mental disorders in the elderly population and specifically among $\mathrm{NH}$ patients. Therefore, finding new interventions to increase well-being and decrease depression among $\mathrm{NH}$ patients is highly warranted. The aim of this study was to explore the association 
TABle 3: SEM analysis. Model $1^{1}$. Standardized gamma ${ }^{2}$. Total ${ }^{3}$ effects of self-transcendence (ST) on nursing home patients' depression.

\begin{tabular}{lcccc}
\hline Construct & \multicolumn{2}{c}{ Parameter } & $\begin{array}{c}\text { LISREL } \\
\text { estimate }\end{array}$ & $t$-value \\
\hline ST-1 to HADS-D & \multicolumn{2}{c}{$\gamma 1,1$} & -0.32 & $-3.01^{*}$ \\
ST-2 to HADS-D & \multicolumn{2}{c}{$\gamma 1,2$} & -0.40 & $-3.43^{*}$ \\
\multicolumn{4}{c}{ Total effects of self-transcendence on depression (HADS-D) } \\
\\
ST-1 & $t$-value & ST-2 & $t$-value \\
HADS2 & -0.18 & $-3.01^{*}$ & -0.23 & $-3.43^{*}$ \\
HADS4 & -0.18 & $-3.13^{*}$ & -0.23 & $-3.30^{*}$ \\
HADS6 & -0.15 & $-2.93^{*}$ & -0.19 & $-3.07^{*}$ \\
HADS8 & -0.11 & $-2.87^{*}$ & -0.14 & $-2.64^{*}$ \\
HADS10 & -0.08 & -1.88 & -0.10 & $-2.41^{*}$ \\
HADS12 & -0.17 & $-2.40^{*}$ & -0.22 & $-4.33^{*}$ \\
\hline
\end{tabular}

Note. ${ }^{*}$ Significant at the $5 \%$ level. ${ }^{1}$ Model 1 : comprising six HADS variables and $10 \mathrm{ST}$ variables. ${ }^{2}$ Gamma standardized regression coefficients representing directional relationships between ST and depression. ${ }^{3}$ Total effect represent the total influence of the explanatory variable on depression.

between interpersonal and intrapersonal self-transcendence and depression in cognitively intact nursing home patients. By doing so we sought to contribute to a holistic nursing perspective of promoting well-being in $\mathrm{NH}$ patients in two ways: first, this study supplies empirical knowledge to the growing body of self-transcendence knowledge by exploring self-transcendence among $\mathrm{NH}$ patients; second, by applying a two-factor construct of self-transcendence [56] that has been shown to be psychometrically superior the onefactor construct, the present study allows a more complex examination of the associations between self-transcendence and depression. The present study examines the relationships and the influences of interpersonal and intrapersonal selftranscendence on depression in NH patients. By means of advanced statistical analysis such as structural equation modeling (SEM), this study provides more specific guidelines to nursing interventions promoting well-being in $\mathrm{NH}$ patients and suggests that finding ways to enhance an individual's intrapersonal and interpersonal self-transcendence might be beneficial in this matter.

More specifically, we found that the hypothesized relationship between self-transcendence (intrapersonal and interpersonal) and depression was fully supported. As hypothesized, interpersonal self-transcendence was negatively associated with depression. It is reasonable that interpersonal self-transcendence including personal interests, learning, involvement with others, connectedness, sharing one's wisdom, and helping others is associated with low depression. Therefore, nursing interventions facilitating $\mathrm{NH}$ patients' involvement and connectedness, sharing wisdom, and possibilities helping others might decrease and prevent depression.

Also, the intrapersonal self-transcendence comprising $\mathrm{NH}$ patients' self-acceptance as growing older, adjusting well to the changes in physical abilities and the present situation, and finding meaning in one's past experiences related negatively to depression. The statistical tests suggested that the intrapersonal self-transcendence affects depression more than the interpersonal self-transcendence among cognitively intact $\mathrm{NH}$ patients. Therefore, staff nurses' awareness of $\mathrm{NH}$ patients' self-acceptance and adjustment to the life situation is essential for well-being as well as enjoyment, humor, and laughter. Supporting NH patients' effort to accept themselves and adjust well to the life situation and one's declines is significant to decrease and prevent depression.

At 86 years old (mean age in the present study), representing the "old old" [4] living in a NH represents a life perspective where openness to keep learning, enjoying hobbies and interests, and involving with others might seem less important than accepting oneself and adjusting well to the "here-and-now" in the NH environment. Loss of functions, relationships, privacy, self-determination, and connectedness and the forthcoming death, together with searching for meaning in the in-house institutionalized $\mathrm{NH}$ life, seem in general as the main challenges. Generally $\mathrm{NH}$ patients are in great need of care and assistance because of physical declines and other limitations, and they represent a vulnerable group. From this particular point of view, $\mathrm{NH}$ patients' energy to create good experiences seems low. Therefore, these individuals need initiative and vitalization from others and the environment. Elderly who lack social/emotional support tend to report more depression [9]. Consequently, the nurse-patient relationships might be an overriding figure in the $\mathrm{NH}$ patients' daily life and might serve as a vital resource of human involvement, interaction, connectedness, and a facilitator of meaningful in-house activities for $\mathrm{NH}$ patients [71].

Few social relations for dialogue, self-reflection, and connectedness are left; in our sample only $19 \%$ had a partner. The social climate in a NH environment is largely determined by the staff-patient interactions that take place within it [72]. The potentials for self-transcendence and well-being are important considerations in $\mathrm{NH}$ care; the participants had stayed in $\mathrm{NH}$ for 6 months or longer. Because the length of stay is long, much time is available to enter into meaningful relationships and communication with patients, pursuing appropriate interventions to promote self-transcendence. Within Erikson's model of human psychosocial development [32], adulthood is concerned with generativity versus stagnation and maturity with ego integrity versus despair. Therefore, self-transcendence as an individual developmental process toward personal maturity and a resource for well-being might serve as an indicator of successful aging among $\mathrm{NH}$ patients.

Some of the intrapersonal self-transcendence indicators loaded low and displayed low $R^{2}$-values. These items involve finding meaning in past experiences, accepting death as a part of life, letting others help, and enjoying one's pace of life. Being in the "fourth age," living in a NH, represents a life situation where letting others help and accepting death are quite obvious. NH patients' daily life is strongly influenced by the routines and availability of help and support from the staff nurses. In this regard, $\mathrm{NH}$ patients might find that they do not have their own pace of life, and enjoying one's pace of life seems less relevant. Also the items "I feel as I'm 
slowed down" and "I have lost interest in my appearance" loaded low, but the composite reliability was good. The low values might indicate that these items are less relevant for this particular sample.

\section{Limitations}

This study expands previous studies by testing the associations between the two-factor construct of self-transcendence and depression among $\mathrm{NH}$ patients by using structural equation modeling. Using SEM accounts for random measurement error and the psychometric properties of the scales in the model are more accurately derived. Nevertheless, the findings of this study must be discussed with some limitations in mind.

First, Model 1 comprises 20 variables, indicating a desirable $N=200$, while in the present study $N=185$. A larger sample would significantly increase the statistical power of the tests. A second limitation concerns the use of self-reported data, which implies a certain risk that the findings are based on common-method variance [73].

Moreover, the fact that the researchers visited the participants to help fill in the questionnaires might have introduced some bias into the respondents' reporting. The questionnaires were part of a battery of nine questionnaires with 130 items. Therefore, frail older NH patients might become exhausted when completing the questionnaires, which may cause a possible bias. To avoid such a bias, experienced researchers were carefully picked and trained in conducting the interviews following a standardised procedure, including small breaks on specific points during the interview process. This procedure worked out very well; in just three cases the interviews had to be completed the next day due to respondent's fatigue. Actually, most participants were even more vigorous after completing the interview.

The NFI and GFI were lower than the recommended value of 0.90 for both indices, indicating uncertainty regarding the associations in Model 1. However, the NFI and GFI are sensitive to small samples, underestimating fit for samples less than 200; therefore they should not be relied on solely [70]. Nevertheless, the CFI is a revised form of the NFI that considers the sample size and performs well even when sample size is small [74]. CFI in the present study was 0.96 , supporting Model 1. In addition, AGFI is an adjusted form of GFI that accounts for the degrees of freedom and was inside the recommended cut-off value.

\section{Relevance to Clinical Nursing}

According to the European Commission's Green Paper on mental health [5], depression is one of the most prevalent mental health problems facing European citizens today. Taking into account the highly chronic nature of these psychological states, we consider our findings noteworthy in their suggestion that self-transcendence might impair the level of depression. Knowledge of how self-transcendence and depression relate to each other in this respect is important for researchers, nurses, and clinicians.
This study demonstrates that both intrapersonal and interpersonal self-transcendence influence depression. Accordingly, facilitating nursing intervention to provide patients' self-transcendence would promote integrity and well-being and prevent despair and depression. The results suggest that the intrapersonal self-transcendence affects depression stronger than the interpersonal self-transcendence among cognitively intact $\mathrm{NH}$ patients. This might indicate that facilitating self-acceptance and helping patients adjust well are crucial to decreasing depression among $\mathrm{NH}$ patients. Furthermore, connecting with others, sharing wisdom, and helping others when possible appear as vital to preventing depression and increasing well-being in cognitively intact $\mathrm{NH}$ patients.

Due to a combination of factors such as patients' communication impairment, clinicians' focus on treating medical conditions, normalization of depression in later life, and a lack of training in mental health among staff in NHs, depression can easily go undetected among the $\mathrm{NH}$ population $[75,76]$. Therefore, self-transcendence might serve as a framework for staff nurses' awareness, assessing patients' mood, and connectedness resources. Staff nurses are increasingly aware that good nursing care consists of more than the competent performance of a number of nursing activities. However, for many nurses, it is much less clear what this "more" means and what importance it has in nursing. Nurses may encourage self-transcendence by facilitating patients' connections with others, stimulating inner reflections and connection to their inner thoughts and emotions, and by promoting spiritual faith, facilitating hobbies, helping others, and sharing wisdom. Enhancing acceptance of the self, death, and one's life situation might prevent and decrease depression among $\mathrm{NH}$ patients. As connectedness is described as the core of self-transcendence, offering connectedness might be a central aspect of $\mathrm{NH}$ care. The interpersonal relationship in patient-nurse interactions has been found to be an essential factor of quality of care, as perceived by long-term care patients $[71,77,78]$. Nurse-patient interaction can help $\mathrm{NH}$ patients preserve their dignity, identity, and integrity [79]. By means of listening to the patients, communicating, and treating the patients with respect, by using empathic understanding, and acknowledging him/her as a person who is to be taken seriously and attended to, staff nurses might promote selftranscendence and therefore personal maturity, decreased depression, and enhanced well-being [71, 80-84].

Nursing research and education should pay more attention to interventions promoting self-transcendence and wellbeing in order to develop a more comprehensive and practice-based view of good nursing care that inspires $\mathrm{NH}$ staff nurses as they perform their daily care practices. More research of the effectiveness of such strategies is highly needed. Educational nursing curricula should underline and facilitate nurse-patient interaction and interventions to expand $\mathrm{NH}$ patients' personal self-boundaries. Advancing the staff nurses' presence with the patient might contribute to increased self-transcendence and decreased depression. 


\section{Conclusion}

The present study suggests that self-transcendence negatively and significantly affects depression in cognitively intact $\mathrm{NH}$ patients. Depression was significantly influenced by the interpersonal and the intrapersonal self-transcendence. Consequently, nursing interventions and in-house activities aiming to increase patients' self-transcendence might have a great impact on $\mathrm{NH}$ patients' depression and their wellbeing.

\section{Conflict of Interests}

No conflict of interests has been declared by the authors.

\section{Acknowledgments}

The authors wish to acknowledge the Sør-Trøndelag University College Faculty of Nursing to support this study, as well as the elderly patients who voluntarily participated in the study.

\section{References}

[1] US Census Bureau. An Aging World, 2008-2009.

[2] OECD. Aging Populations: Social Policy Implications. Paris, France, 1988.

[3] P. B. Baltes and J. Smith, "New frontiers in the future of aging: from successful aging of the young old to the dilemmas of the fourth age," Gerontology, vol. 49, no. 2, pp. 123-135, 2003.

[4] M. Kirkevold, Ed., Translating Chronic Illness Researc across the Lifespan, Blackwell Publishing, Oxford, UK, 1st edition, 2010.

[5] COM, Green Paper, 484, Improving the mental health of the population: Towards a strategy on mental health for the European Unioin Brussels: European Communities, 2005.

[6] F. Lattanzio, M. Di Bari, A. Sgadari et al., "Improving the diagnostic accuracy of depression in older persons: the depression in the aged female national evaluation cluster randomized trial: clinical investigations," Journal of the American Geriatrics Society, vol. 57, no. 4, pp. 588-593, 2009.

[7] J. K. Djernes, "Prevalence and predictors of depression in populations of elderly: a review," Acta Psychiatrica Scandinavica, vol. 113, no. 5, pp. 372-387, 2006.

[8] K. Jongenelis, A. M. Pot, A. M. H. Eisses, A. T. F. Beekman, H. Kluiter, and M. W. Ribbe, "Prevalence and risk indicators of depression in elderly nursing home patients: the AGED study," Journal of Affective Disorders, vol. 83, no. 2-3, pp. 135-142, 2004.

[9] S. Grav, O. Hellzèn, U. Romild, and E. Stordal, "Association between social support and depression in the general population: the HUNT study, a cross-sectional survey," Journal of Clinical Nursing, vol. 21, no. 1-2, pp. 111-120, 2012.

[10] K. Jongenelis, A. M. Pot, A. M. H. Eisses et al., "Depression among older nursing home patients: a review," Tijdschrift voor Gerontologie en Geriatrie, vol. 34, no. 2, pp. 52-59, 2003.

[11] E. Stordal, A. Mykletun, and A. A. Dahl, "The association between age and depression in the general population: a multivariate examination," Acta Psychiatrica Scandinavica, vol. 107, no. 2, pp. 132-141, 2003.

[12] E. Stordal, M. Bjartveit Krüger, N. H. Dahl, O. Krüger, A. Mykletun, and A. A. Dahl, "Depression in relation to age and gender in the general population: the Nord-Trøndelag health study (HUNT)," Acta Psychiatrica Scandinavica, vol. 104, no. 3, pp. 210-216, 2001.

[13] M. L. Barca, G. Selbæk, J. Laks, and K. Engedal, "Factors associated with depression in Norwegian nursing homes," International Journal of Geriatric Psychiatry, vol. 24, no. 4, pp. 417-425, 2009.

[14] R. C. Kessler, P. Berglund, O. Demler et al., "The epidemiology of major depressive disorder: results from the National Comorbidity Survey Replication (NCS-R)," Journal of the American Medical Association, vol. 289, no. 23, pp. 3095-3105, 2003.

[15] M. Smalbrugge, L. Jongenelis, A. M. Pot, A. T. F. Beekman, and J. A. Eefsting, "Comorbidity of depression and anxiety in nursing home patients," International Journal of Geriatric Psychiatry, vol. 20, no. 3, pp. 218-226, 2005.

[16] D. De Leo, R. Rozzini, D. Conforti et al., "Anxiety symptoms and disorders in institutionalized elderly free from signs of dementia," New Trends in Experimental and Clinical Psychiatry, vol. 9, no. 1-2, pp. 31-35, 1993.

[17] P. Parmelee, I. Katz, and M. Lawton, "Anxiety and its association with depression among institutionalized elderly," American Journal of Geriatric Psychiatry, vol. 1, pp. 46-58, 1993.

[18] M. Smalbrugge, L. Jongenelis, A. M. Pot, J. A. Eefsting, M. W. Ribbe, and A. T. F. Beekman, "Incidence and outcome of depressive symptoms in nursing home patients in the Netherlands," American Journal of Geriatric Psychiatry, vol. 14, no. 12, pp. 1069-1076, 2006.

[19] R. Rozzini, S. Boffelli, and S. Franzoni, "Prevalence and predictors of depressive symptoms in a nursing home," International Journal of Geriatric Psychiatry, vol. 11, pp. 629634, 1996.

[20] T. Gonzalez-Salvador, C. Lyketsos, A. Baker, L. Hovanec, C. Roques, and J. Brandt, "Quality of life in dementia patients in long-term care," International Journal of Geriatric Psychiatry, vol. 15, pp. 181-189, 2000.

[21] H. Koenig and D. Blazer, "Mood disorders," in Textbook of Geriatric Psychiatry, D. Blazer, D. Steffens, and F. Busse, Eds., pp. 241-268, American Psychiatric Publishing, Washington, DC, USA, 3rd edition, 2004.

[22] D. K. Y. Miu and C. K. Chan, "Prognostic value of depressive symptoms on mortality, morbidity and nursing home admission in older people," Geriatrics and Gerontology International, vol. 11, no. 2, pp. 174-179, 2011.

[23] L. C. Watson, J. M. Garrett, P. D. Sloane, A. L. GruberBaldini, and S. Zimmerman, "Depression in assisted living: results from a four-state study," American Journal of Geriatric Psychiatry, vol. 11, no. 5, pp. 534-542, 2003.

[24] M. Smalbrugge, A. M. Pot, L. Jongenelis, C. M. Gundy, A. T. F. Beekman, and J. A. Eefsting, "The impact of depression and anxiety on well being, disability and use of health care services in nursing home patients," International Journal of Geriatric Psychiatry, vol. 21, no. 4, pp. 325-332, 2006.

[25] G. Namkee, S. R. Choi, and J. W. Richard, "Depression in older nursing home residents: the influence of nursing home environmental stressors, coping, and acceptance of group and individual therapy," Aging and Mental Health, vol. 12, no. 5, pp. 536-547, 2008.

[26] S. Meeks, S. N. Shah, and S. K. Ramsey, "The pleasant events schedule-nursing home version: a useful tool for behavioral interventions in long-term care," Aging and Mental Health, vol. 13, no. 3, pp. 445-455, 2009.

[27] C. Konnert, K. Dobson, and L. Stelmach, "The prevention of depression in nursing home residents: a randomized clinical 
trial of cognitive-behavioral therapy," Aging and Mental Health, vol. 13, no. 2, pp. 288-299, 2009.

[28] WHO. World Health Report, 2001.

[29] D. D. Coward, "Self-transcendence and emotional well-being in women with advanced breast cancer," Oncology Nursing Forum, vol. 18, no. 5, pp. 857-863, 1991.

[30] C. R. Ellermann and P. G. Reed, "Self-transcendence and depression in middle-age adults," Western Journal of Nursing Research, vol. 23, no. 7, pp. 698-713, 2001.

[31] P. G. Reed, "Self-transcendence and mental health in oldestold adults," Nursing Research, vol. 40, no. 1, pp. 5-11, 1991.

[32] E. H. Erikson, Childhood and Society, W. W. Norton \& Company, New York, NY, USA, 1950.

[33] P. G. Reed, “Theory of self-transcendence," in Middle Range Theory for Nursing, M. J. Smith and P. R. Liehr, Eds., pp. 105129, Springer, New York, NY, USA, 2008.

[34] J. Quinn, "Transpersonal human caring and healing," in Holistic Nursing A Handbook for Practice, B. Dossey, L. Keegan, and C. Guzzetta, Eds., pp. 41-53, Jones and Bartlett, London, UK, 2005.

[35] M. A. Burkhardt and M. G. Nagai-Jacobson, "Reawakening spirit in clinical practice," Journal of Holistic Nursing, vol. 12, no. 1, pp. 9-21, 1994.

[36] H. G. Buck, "Spirituality: concept analysis and model development," Holistic Nursing Practice, vol. 20, no. 6, pp. 288-292, 2006.

[37] B. Pesut, "A conversation on diverse perspectives of spirituality in nursing literature," Nursing Philosophy, vol. 9, no. 2, pp. 98$109,2008$.

[38] D. Miner-Williams, "Putting a puzzle together: making spirituality meaningful for nursing using an evolving theoretical framework," Journal of Clinical Nursing, vol. 15, no. 7, pp. 811821, 2006.

[39] L. Chiu, J. Emblen, L. Van Hofwegen, R. Sawatzky, and H. Myerhoff, "An integrative review of the concept of spirituality: a literature review," Western Journal of Nursing Research, vol. 26, pp. 1183-1188, 2004.

[40] G. Haugan, T. Rannestad, R. Hammervold, H. Garåsen, and G. A. Espenes, "The associations between self-transcendence and spiritual well-being in cognitively intact nursing home patients," International Journal of Older People Nursing. In press.

[41] J. Drageset, Health-Related Quality of Life among Nursing Home Residents, Department of Public Health and Primary Health Care, Section of Nursing Sciences, University of Bergen, Bergen, Norway, 2009.

[42] S. Nakrem, A. G. Vinsnes, and A. Seim, "Residents' experiences of interpersonal factors in nursing home care: a qualitative study," International Journal of Nursing Studies, vol. 48, no. 11, pp. 1357-1366, 2011.

[43] P. G. Reed, "Nursing: the ontology of the discipline," in Perspectives on Nursing Theory, P. G. Reed and N. B. C. Shearer, Eds., pp. 615-620, Wolters Kluwer-Lippincott Williams \& Wilikns, Tokyo, Japan, 2009.

[44] K. D. Kausch and K. Amer, "Self-transcendence and depression among AIDS memorial quilt panel makers," Journal of Psychosocial Nursing and Mental Health Services, vol. 45, no. 6, pp. 44-53, 2007.

[45] D. Klaas, "Testing two elements of spirituality in depressed and non-depressed elders," The international Journal of Psychiatric Nursing Research, vol. 4, no. 2, pp. 452-462, 1998.

[46] P. G. Reed, "Demystifying Self-Transcendence for Mental Health Nursing Practice and Research," Archives of Psychiatric Nursing, vol. 23, no. 5, pp. 397-400, 2009.
[47] K. B. Bean and K. Wagner, "Self-transcendence, illness distress, and quality of life among liver transplant recipients," Journal of Theory Construction \& Testing, vol. 10, no. 2, pp. 47-53, 2006.

[48] J. J. Runquist and P. G. Reed, "Self-transcendence and wellbeing in homeless adults," Journal of Holistic Nursing, vol. 25, no. 1, pp. 5-13, 2007.

[49] C. K. Stinson and E. Kirk, "Structured reminiscence: an intervention to decrease depression and increase selftranscendence in older women," Journal of Clinical Nursing, vol. 15, no. 2, pp. 208-218, 2006.

[50] S. S. Chin-A-Loy and J. I. Fernsler, "Self-transcendence in older men attending a prostate cancer support group," Cancer Nursing, vol. 21, no. 5, pp. 358-363, 1998.

[51] D. D. Coward and P. G. Reed, "Self-transcendence: a resource for healing at the end of life," Issues in Mental Health Nursing, vol. 17, no. 3, pp. 275-288, 1996.

[52] M. Teixera, "Self-transcendence, spiritual well-being, and spiritual practices of women with breast cancer," Holistic Nursing Practice, vol. 22, no. 1, pp. 25-31, 2008.

[53] M. Hoshi, Self-Transcendence, Vulnerability, and Well-Being in Hospitalized Japanese Elders, University of Arizona, 2008.

[54] D. D. Coward, "Facilitation of self-transcendence in a breast cancer support group-II," Oncology Nursing Forum, vol. 30, no. 2, pp. 291-300, 2003.

[55] B. Williams, Rebirth: The Experience of Self-Transcendence in Patients who Have Undergone Stem Cell Transplantation, New York University, New York, NY, USA, 2008.

[56] G. Haugan, T. Rannestad, R. Hammervold, H. Garåsen, and G. A. Espnes, "The self-transcendence scale-an investigation of the factor structure among nursing home patients," Journal of Holistic Nursing. In press.

[57] R. Snaith and A. Zigmond, "The hospital anxiety and depression scale manual," NEFER-Nelson, Windsor, UK, 1994.

[58] C. Herrmann, "International experiences with the hospital anxiety and depression scale - A review of validation data and clinical results," Journal of Psychosomatic Research, vol. 42, no. 1, pp. 17-41, 1997.

[59] P. G. Reed, "Developmental resources and depression in the elderly," Nursing Research, vol. 35, no. 6, pp. 368-374, 1986.

[60] D. D. Coward, "The lived experience of self-transcendence in women with advanced breast cancer," Nursing Science Quarterly, vol. 3, no. 4, pp. 162-169, 1990.

[61] D. D. Coward, "Self-transcendence and correlates in a healthy population," Nursing Research, vol. 45, no. 2, pp. 116-121, 1996.

[62] B. Nygren, L. Alex, E. Jonsen, Y. Gustafson, A. Norberg, and B. Lundman, "Resilience, sense of coherence, purpose in life and self-transcendence in relation to perceived physical and mental health among the oldest old," Aging and Mental Health, vol. 9, no. 4, pp. 354-362, 2009.

[63] A. Diamantopolous and J. A. Siguaw, Introducing LISREL, SAGE, London, UK, 2008, Edited by D. B. Wright.

[64] K. Jøreskog and D. Sørbom, LISREL 8: Structural Equation Modeling with the SIMPLIS Command Language, Scientific Software International, Chicago, Ill, USA, 1995.

[65] K. Jøreskog, D. Sørbom, S. du Toit, and M. du Toit, New Statistical Features, Scientific Software International, Chicago, Ill, USA, 2000.

[66] K. Schermelleh-Engel, H. Moosbrugger, and H. Muller, "Evaluating the fit of structural equation models: tests of significance and descriptive goodness-of-fit measures," Methods of Psychological Research, vol. 8, no. 2, pp. 23-74, 2003.

[67] L. T. Hu and P. M. Bentler, "Fit indices in covariance structure modeling: sensitivity to underparameterized model 
misspecification," Psychological Methods, vol. 3, no. 4, pp. 424453, 1998.

[68] J. C. Nunally and I. H. Bernstein, Psychometric Theory, McGraw-Hill, New York, NY, USA, 1994.

[69] P. M. Bentler, "Comparative fit indexes in structural models," Psychological Bulletin, vol. 107, no. 2, pp. 238-246, 1990.

[70] R. B. Kline, Principles and Practice of Structural Equation Modeling, The Guilford Press, London, UK, 2nd edition, 2005, Edited by D. A. Kenny.

[71] G. Haugan Hovdenes, "The Nurse-patient-relationship in nursing homes: fulfillment or destruction," Vård i Norden, vol. 22, no. 3, article 65, pp. 21-26, 2002.

[72] S. H. Zarit, M. M. Dolan, and S. A. Leitsch, "Interventions in nursing homes and other alternative living settings," in Clinical Geropsychology, I. H. Nordhus, G. R. VandenBos, S. Berg, and P. Fromholt, Eds., American Psychological Association, Washington, DC, USA, 1998.

[73] P. M. Podsakoff, S. B. MacKenzie, J. Y. Lee, and N. P. Podsakoff, "Common method biases in behavioral research: a critical review of the literature and recommended remedies," Journal of Applied Psychology, vol. 88, no. 5, pp. 879-903, 2003.

[74] D. Hooper, J. Coughlan, and M. R. Mullen, "Structural equation modelling: guidelines for determining model fit," The Electronic Journal of Business Research Methods, vol. 6, no. 1, pp. 53-60, 2008.

[75] H. Bagley, L. Cordingey, A. Burns, C. Mozley, C. Sutcliff, and D. Challis, "Recognition of depression by staff in nursing and residential homes," Journal of Clinical Nursing, vol. 9, pp. 445450, 2000.

[76] L. Martin, J. W. Poss, J. P. Hirdes, R. N. Jones, M. J. Stones, and B. E. Fries, "Predictors of a new depression diagnosis among older adults admitted to complex continuing care: implications for the depression rating scale (DRS)," Age and Ageing, vol. 37, no. 1, pp. 51-56, 2008.

[77] A. Bergland and M. Kirkevold, "Thriving in nursing homes in Norway: contributing aspects described by residents," International Journal of Nursing Studies, vol. 43, no. 6, pp. 681691, 2006.

[78] C. B. Wilson and S. Davies, "Developing relationships in long term care environments: the contribution of staff," Journal of Clinical Nursing, vol. 18, no. 12, pp. 1746-1755, 2009.

[79] R. Coughlan and L. Ward, "Experiences of recently relocated residents of a long-term care facility in Ontario: assessing quality qualitatively," International Journal of Nursing Studies, vol. 44, no. 1, pp. 47-57, 2007.

[80] C. Jonas-Simpson, G. J. Mitchell, A. Fisher, G. Jones, and J. Linscott, "The experience of being listened to: a qualitative study of older adults in long-term care settings," Journal of Gerontological Nursing, vol. 32, no. 1, pp. 46-53, 2006.

[81] L. P. Finch, "Patients' communication with nurses: relational communication and preferred nurse behaviors," International Journal for Human Caring, vol. 10, no. 4, pp. 14-22, 2006.

[82] N. Hollinger-Samson and J. L. Pearson, "The relationship between staff empathy and depressive symptoms in nursing home residents," Aging and Mental Health, vol. 4, no. 1, pp. $56-65,2000$.

[83] M. V. Asmuth, "Developing and sustaining interpersonal relationships between certified nursing assistants and residents in long-term care facilities," University of South Florida, 2004.

[84] G. Haugan, T. Rannestad, B. Hansen, and G. A. Espens, "Selftranscendence and nurse-patient interaction in cognitively intact nursing home patients," Journal of Clinical Nursing. In press. 


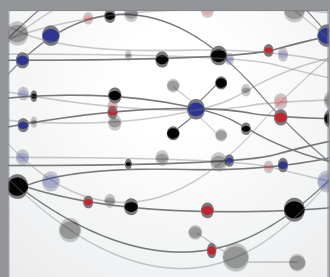

The Scientific World Journal
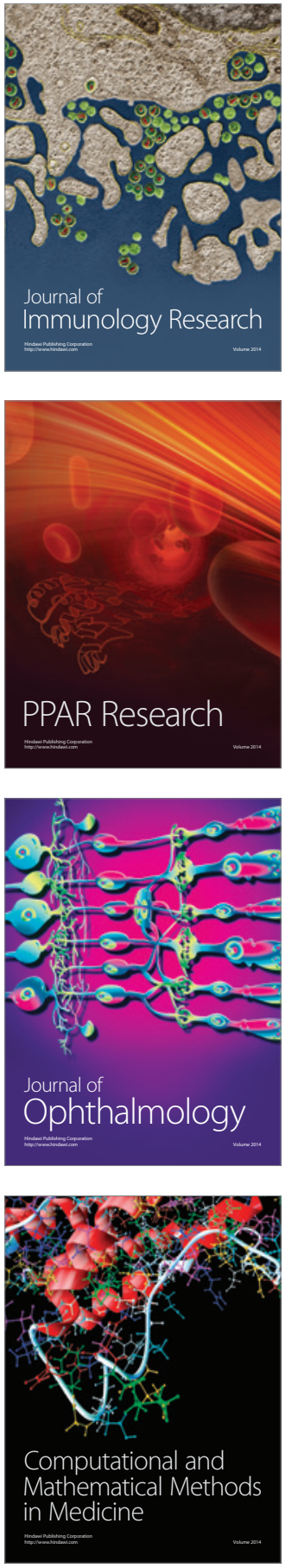

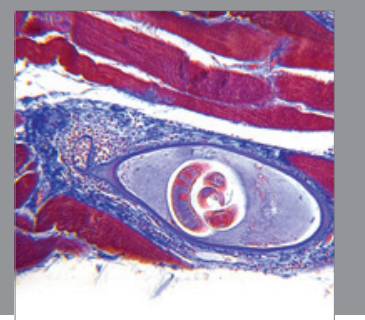

Gastroenterology

Research and Practice
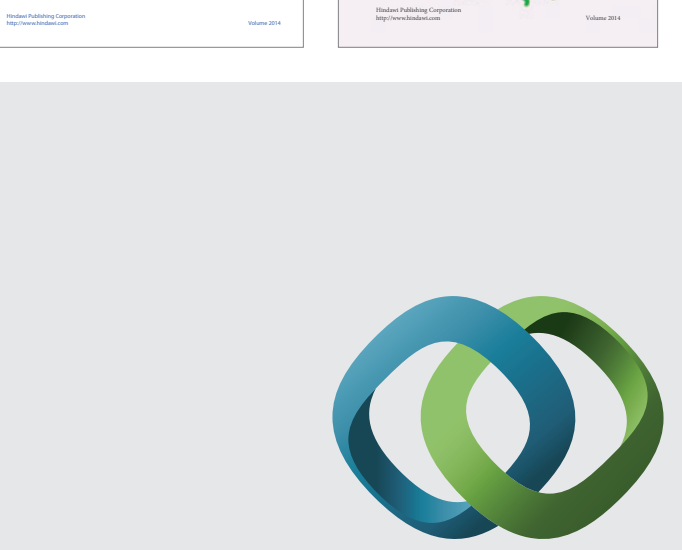

\section{Hindawi}

Submit your manuscripts at

http://www.hindawi.com
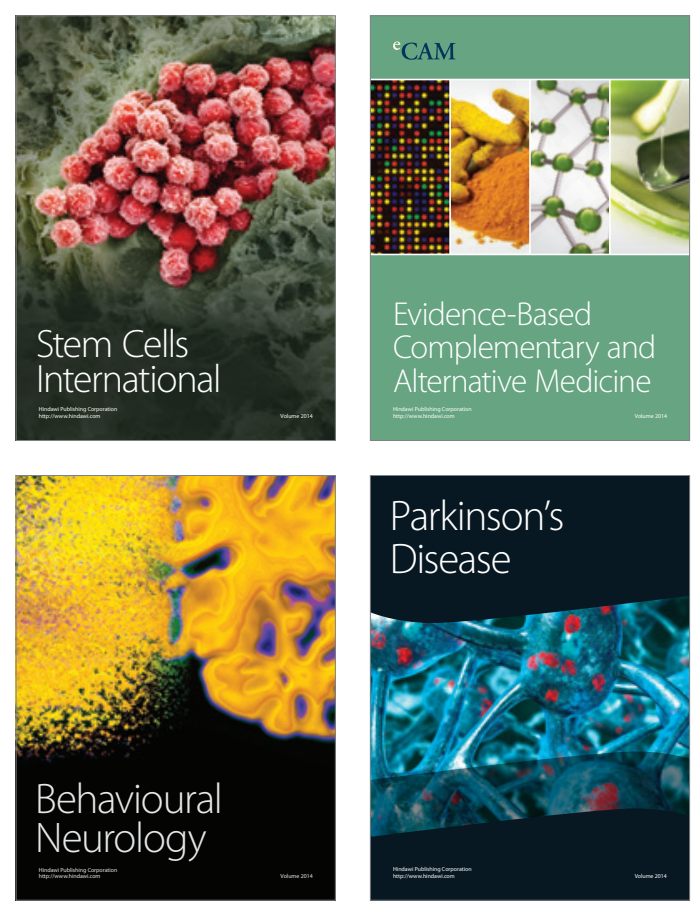

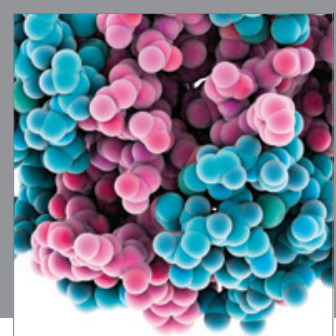

Journal of
Diabetes Research

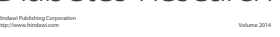

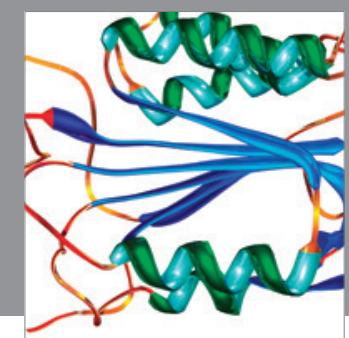

Disease Markers
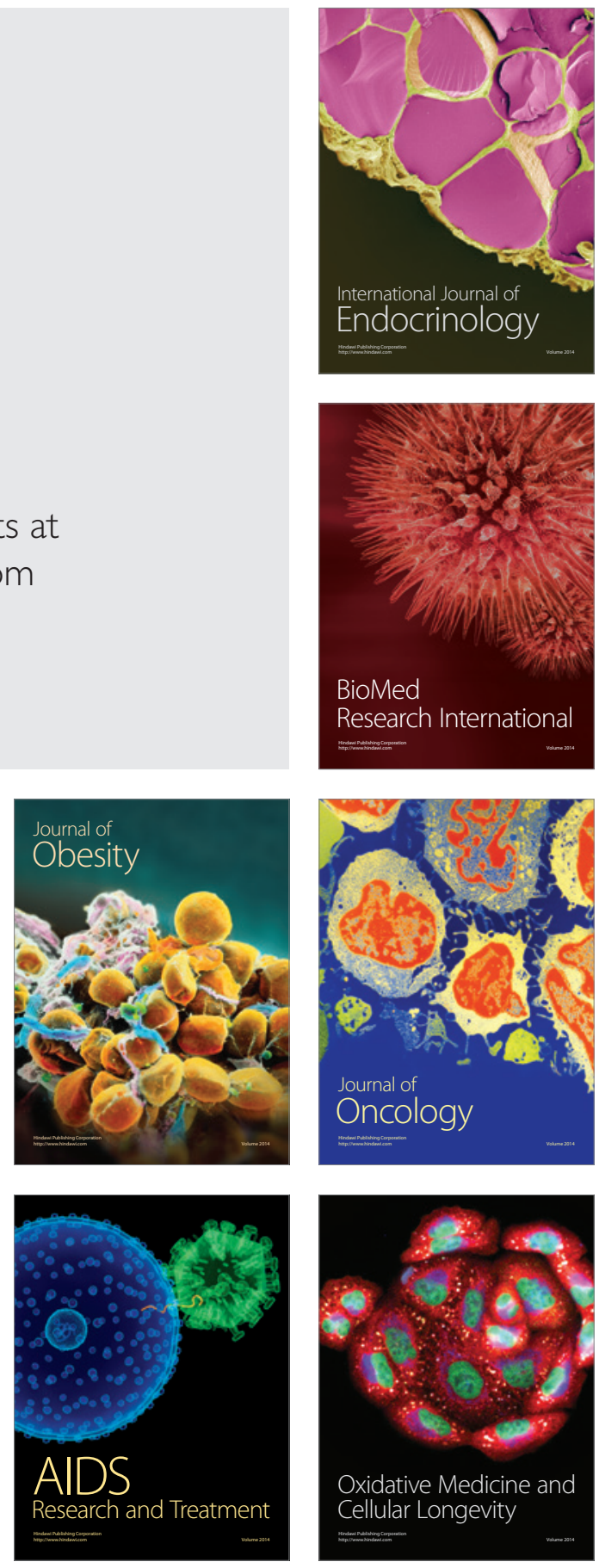